\title{
RESISTÊNCIA DE LINHAGENS AVANÇADAS DE TOMATEIRO A TOSPOVÍRUS ${ }^{(1)}$
}

\author{
ANDRÉ LUIZ LOURENÇÃO ${ }^{(2,8)}$, HIROSHI NAGAI(3), WALTER JOSÉ SIQUEIRA ${ }^{(4)}$, \\ ARLETE MARCHI TAVARES DE MELO ${ }^{(3)}$, JOSÉ ALFREDO USBERTI FILHO ${ }^{(5,8)}$, \\ LEONARDO COSTA DA FONTE ${ }^{(6)} \&$ PAULO CÉSAR TAVARES DE MELO ${ }^{(7)}$
}

\begin{abstract}
RESUMO
Linhagens avançadas de tomateiro resultantes do programa de melhoramento do Instituto Agronômico, Campinas (IAC) foram avaliadas em relação à resistência a tospovírus, à produtividade e ao teor de sólidos solúveis em condições de campo. Em 1995/96, as linhagens IAC S4-3, IAC S4-4, IAC S4-13 e IAC S4-17 comportaram-se como resistentes a tospovírus em Campinas (SP) e em Petrolina (PE), apresentando a IAC S4-17, na última localidade, níveis de produtividade próximos aos do AG-45, o cultivar mais produtivo, porém considerado suscetível a tospovírus. Em 1996/97, em Campinas, linhagens derivadas de outras fontes de resistência a tospovírus exibiram, em condições de telado, níveis de resistência inferiores aos das derivadas de 'Stevens'. Nesse mesmo ano agrícola e local, em campo, dez seleções feitas nas linhagens do grupo IAC S4, para tamanho e firmeza de frutos, apresentaram resistência aos isolados locais de tospovírus. Nove novas seleções, nesse germoplasma, foram comparadas em campo, em 1997/98, com quatro linhagens e um cultivar desenvolvidos pela SVS do Brasil Sementes Ltda: o nível de infecção devido a tospovírus variou de 70,3 ('Colosso') até 8,6\% (IAC S4-4-16G), atingindo 100\% na testemunha suscetível, IPA-6.
\end{abstract}

\footnotetext{
(1) Parcialmente financiado pelas Indústrias Gessy Lever Ltda. Recebido para publicação em 13 de novembro de 1998 e aceito em 2 de setembro de 1999.

(2) Centro de Fitossanidade, Instituto Agronômico (IAC), Caixa Postal 28, 13001-970 Campinas (SP).

${ }^{(3)}$ Centro de Horticultura (IAC).

(4) Centro de Genética, Biologia Molecular e Fitoquímica (IAC).

${ }^{(5)}$ Centro de Plantas Graníferas (IAC).

${ }^{(6)}$ Indústrias Gessy Lever Ltda., Av. Cica 1.000, 38700-000 Patos de Minas (MG).

(7) SVS do Brasil Sementes Ltda., Caixa Postal 102, 13140-000 Paulínia (SP).

${ }^{(8)} \mathrm{Com}$ bolsa de produtividade em pesquisa do CNPq.
} 
Em Patos de Minas (MG), em 1997, as linhagens IAC S4-3-10 e IAC S4-3-18H revelaram valores de brix intermediários entre os cultivares IPA-5 e AG-45, este, o de melhor desempenho nessa característica; em relação à produtividade, as duas linhagens IAC tiveram as mais altas produções, embora com crescimento vegetativo vigoroso e ciclo longo.

Termos de indexação: Lycopersicon spp., resistência varietal a vírus.

\section{ABSTRACT \\ TOSPOVIRUS RESISTANCE OF TOMATO ADVANCED LINES}

Tomato advanced lines, obtained in the IAC breeding program, were recently evaluated, under different Brazilian states producing areas to tospovirus reaction, fruit yield and soluble solid contents. In the growing season 95/96, IAC S4-3, IAC S4-4, IAC S4-13 and IAC S4-17, behaved as tospovirus resistant in Campinas, State of São Paulo, and Petrolina, State of Pernambuco; IAC S4-17, in the last site, showed productivity levels similar to that of AG-45, which is highly productive but susceptible to the disease. During the growing season 96/97, evaluation carried out under greenhouse conditions, in Campinas, showed that the ten selections above mentioned lines presented higher levels of Tospovirus resistance as compared to other tomato lines derived from different resistance sources. Nine new lines selected within the IAC S4-group were tested under field trials (Campinas), during the growing season 97/98, and compared to cultivars Colosso (SVS), Stevens and IPA-6 and four SVS lines. Tospovirus infection levels varied from $8.6 \%$ (IAC S4-4-16G) to 100\% (IPA-6), with cultivars Stevens and Colosso reaching $31.7 \%$ and $70.3 \%$, respectively. Also in 97, under field conditions in Patos de Minas, State of Minas Gerais, tomato lines IAC S4-3-10 and IAC S4-3-18H presented soluble solid contents similar to that of AG-45, considered outstanding for the character. They also showed higher fruit yields than cultivars AG-45 and IPA-5, although showing excessively late flowering and fruit maturing cycles.

Index terms: Lycopersicon spp., virus resistance.

\section{INTRODUÇÃO}

Atualmente, o gênero Tospovirus (família Bunyaviridae) apresenta as seguintes espécies: "tomato spotted wilt virus" (TSWV), "Impatiens necrotic spot virus" (INSV), "tomato chlorotic spot virus" (TCSV), "groundnut ringspot virus” (GRSV), "watermelon silver mottle virus" (WSMV), "groundnut bud necrosis virus" (GBNV), "Iris yellow spot virus" (IYSV), "zucchini lethal chlorosis virus" (ZLCV) e "Chrysanthemum stem necrosis virus" (CSNV) (Ávila et al., 1998). Os tospovírus causam, como sintomas principais, anéis necróticos ou cloróticos nas folhas e nos frutos infectados, mosaico, arroxeamento ou bronzeamento nas folhas, nanismo, deformação foliar, necrose severa das hastes e das folhas, e, muito freqüentemente, morte da planta, podendo atingir "status" de doença limitante em culturas de expressão econômica em várias regiões do mundo (German et al., 1992; Pozzer et al., 1996). No Brasil, a doença, conhecida como "viracabeça do tomateiro", de grande importância nas épocas quentes do ano, foi relatada pela primeira vez por Costa \& Forster (1938) e, por muito tempo, tida como causada por uma única espécie de vírus, o TSWV (Ie, 1970). 
Em levantamento realizado em seis Estados brasileiros, em 1992/93, Nagata et al. (1995) identificaram três espécies de tospovírus em amostras de plantas de tomateiro com sintomas típicos de "viracabeça": TSWV, com predominância no Distrito Federal e no Paraná; TCSV, predominante em São Paulo, e GRSV, com predomínio em Pernambuco. Posteriormente, Ávila et al. (1996) verificaram que, em plantas infectadas de tomateiro, alface e pimentão da região do submédio São Francisco, apenas GRSV estava presente, ratificando observações de Nagata et al. (1995).

A importância do patógeno, segundo Melo \& Carneiro (1997), é devida à sua rápida disseminação na área cultivada e à ineficiência dos controles cultural e químico. Este último, embora reduzindo as populações dos tripes vetores (pelo menos oito espécies envolvidas, segundo Wijkamp et al., 1995), não tem sido efetivo no controle da doença, em vista de novas migrações de tripes virulíferos de áreas adjacentes. Também deve ser considerada a eficiência diferenciada na transmissão de tospovírus pelas espécies de tripes, já que Wijkamp et al. (1995) demonstraram que Frankliniella occidentalis (Pergande), entre outras três espécies vetoras, foi a mais eficaz, transmitindo quatro espécies de tospovírus; por outro lado, Thrips tabaci (Lind.) teve o pior desempenho, veiculando em baixos níveis apenas uma espécie de tospovírus. Assim, a predominância de uma espécie de tripes em dada região pode influenciar a menor ou maior disseminação das espécies de tospovírus.

Para controle do vira-cabeça, diversas medidas têm sido estudadas, como combate aos tripes vetores, por métodos químicos, físicos ou biológicos, plantas transgênicas e obtenção de cultivares resistentes mediante melhoramento clássico. Nessa última linha, trabalhos têm sido realizados no Brasil e no exterior, procurando-se relacionar germoplasma resistente (Zijl et al., 1986; Maluf et al., 1991; Nagai et al., 1992; Boiteux et al., 1993; Giordano et al., 1994, 1998; Juliatti et al., 1994, 1996; Lourenção et al., 1997; Melo \& Carneiro, 1997; Resende et al., 1998), bem como estudar aspectos da herança da resistência (Stevens et al., 1992; Boiteux \& Giordano, 1993; Juliatti \& Maluf, 1995; Juliatti et al., 1996; Resende et al., 1996).

Neste trabalho, avaliaram-se a resistência a tospovirus, a produtividade e o teor de sólidos solúveis de linhagens avançadas do programa de melhoramento do tomateiro do Instituto Agronômico (IAC) em três Estados brasileiros.

\section{MATERIAL E MÉTODOS}

\subsection{Avaliação de linhagens e cultivares para teor de sólidos solúveis, produtividade e infecção por tospovírus em Petrolina (PE), em 1995}

Seis genótipos de tomateiro, envolvendo quatro linhagens IAC (IAC S4-3, IAC S4-4, IAC S4-13 e IAC S4-17) e dois cultivares (IPA-5 e AG-45) (Quadro 1), foram avaliados em condições de campo, em área experimental da Gessy Lever, localizada no Projeto Senador Nilo Coelho, Petrolina (PE). As linhagens são derivadas de cruzamentos entre Stevens, cultivar desenvolvido na África do Sul e resistente a tospovírus (Stevens, citado por Stevens et al., 1992) e IPA 6, cultivar suscetível, e selecionadas em condições de campo em Campinas (SP) para resistência a tospovírus (Lourenção et al., 1997).

O germoplasma foi semeado em 9/5/95 em bandejas de isopor contendo mistura de composto vegetal e transplantado para campo em 10/6/95. O delineamento experimental utilizado foi de blocos ao acaso, com seis tratamentos e cinco repetições. Cada parcela foi formada por canteiros de $10 \times 1,3 \mathrm{~m}$, tendo a área útil 30 plantas, espaçadas entre si de 0,26 m. Avaliou-se, em cada parcela, a porcentagem de plantas com sintomas de tospovírus e colheram-se frutos para obtenção da produtividade e análise do teor de sólidos solúveis. 


\subsection{Avaliação de infecção por tospovírus em linhagens e cultivares, em Campinas (SP), em 1995/96}

Os mesmos genótipos estudados em Petrolina foram avaliados em condições de campo, em Campinas, em área do Centro Experimental de Campinas (CEC), pertencente ao IAC. O germoplasma foi semeado em 8/11/95 e transplantado para campo em 29/ 11/95. O delineamento foi de blocos ao acaso, com seis tratamentos e seis repetições. Cada parcela constou de três linhas de $3 \mathrm{~m}$, com sete plantas por linha. $\mathrm{O}$ espaçamento foi de $1 \mathrm{~m}$ entre linhas e $0,5 \mathrm{~m}$ entre plantas. Realizaram-se duas avaliações da porcentagem de plantas com sintomas de tospovírus, em 5/1 e $30 / 1 / 96$.

\subsection{Avaliação de infecção por tospovírus em linhagens e cultivares em Campinas (SP), em 1996/97}

Dez linhagens selecionadas no ano anterior, a partir das quatro IAC resistentes a tospovírus (IAC S4-3, IAC S4-4, IAC S4-13 e IAC S4-17), juntamente com os controles 'IPA-5', suscetível, e 'Stevens', resistente (Quadro 2), foram avaliadas em condições de campo no CEC. O germoplasma foi semeado em 6/12 e transplantado para campo em 27/12/96. Utilizou-se o delineamento de blocos ao acaso, com doze tratamentos e quatro repetições. As parcelas constituíram-se de três linhas de $3 \mathrm{~m}$ com dez plantas cada uma. $\mathrm{O}$ espaçamento foi de $1 \mathrm{~m}$ entre linhas e $0,5 \mathrm{~m}$ entre plantas, ocorrendo as avaliações da porcentagem de plantas com sintomas de tospovírus em três datas: $17 / 1,6 / 2$ e 12/3/97.

Um segundo experimento foi instalado em telado, em área ao lado do primeiro, com o objetivo de avaliar a incidência de tospovírus em linhagens do programa de melhoramento do IAC derivadas de outras fontes de resistência a insetos e doenças. Como testemunhas, utilizaram-se 'IPA-5' e as quatro linhagens IAC resistentes (Quadro 3). O telado empregado é protegido por tela cuja malha permite a passagem de insetos do tamanho de tripes, o que proporcionou a ocorrência natural de infecções severas de tospovírus em tomateiros e em alface nesse local em anos anteriores. As datas de semeadura e de transplante foram as mesmas do experimento de campo. O delineamento foi de blocos ao acaso, com catorze tratamentos e quatro repetições. Cada parcela constou de uma linha com sete plantas, com espaçamento de $1 \mathrm{~m}$ entre linhas, efetuando-se duas avaliações da porcentagem de plantas com sintomas de tospovírus em 6/2 e 12/3/ 97.

\subsection{Avaliação de infecção por tospovírus em linhagens e cultivares em Campinas (SP), em 1997/98}

Avaliaram-se em campo, no CEC, na mesma área experimental dos dois anos anteriores, os seguintes materiais: nove seleções feitas em 1996/97 para tamanho e firmeza de frutos nas linhagens IAC com melhor desempenho para resistência a tospovírus; o cultivar Colosso e as linhagens L355-E, L247-97, L248-97 e L250-97, desenvolvidas pela SVS Sementes, e os controles 'Stevens' e 'IPA-6' (Quadro 4). As linhagens e os cultivares foram semeados em 28/11 e transplantados para campo em 22/12/97. O delineamento foi de blocos ao acaso, com dezesseis tratamentos e cinco repetições. As parcelas foram representadas por duas linhas de $3 \mathrm{~m}$, com sete plantas por linha e espaçamento de $1 \mathrm{~m}$ entre linhas. A avaliação de plantas com sintomas de tospovírus foi realizada em duas datas, em 4/2 e 11/3/98.

\subsection{Avaliação de produtividade e de teor de sólidos solúveis em linhagens em Patos de Minas (MG), em 1997}

As linhagens IAC S4-3-10 e IAC S4-3-18H, resistentes a tospovírus, foram comparadas com os cultivares AG-45 e IPA-5, em experimento em duas épocas, em área da Gessy Lever, na região de Patos de Minas. O germoplasma foi semeado em 15/4 para o experimento de primeira época e em 8/5/97 para o 
de segunda, e transplantado para campo, respectivamente, em 19/5 e 12/6/97. O delineamento utilizado foi de blocos ao acaso, com quatro tratamentos e seis repetições. Cada parcela constou de canteiros de $7 \mathrm{~m}$ de comprimento por 1,8 $\mathrm{m}$ de largura, perfazendo uma área de 12,6 $\mathrm{m}^{2}$. Em duas épocas, efetuou-se, em cada parcela, a colheita de frutos para estimativa de produtividade e análise do teor de sólidos solúveis.

\subsection{Análise estatística}

Os dados referentes à porcentagem de plantas com sintomas de tospovírus e ao teor de sólidos solúveis $(\%)$ foram convertidos em arco seno $\sqrt{\% / 100}$ e, os de produtividade (t.ha ${ }^{-1}$ ), não foram transformados. As médias foram comparadas pelo teste de Tukey a 5\%. Para o experimento de Patos de Minas, efetuou-se a análise conjunta para as duas épocas.

\section{RESULTADOS E DISCUSSÃO}

\subsection{Avaliação de linhagens e cultivares para teor de sólidos solúveis, produtividade e infecção por tospovírus em Petrolina (PE), em 1995}

Nessa área experimental, a porcentagem de plantas com sintomas de tospovírus não foi elevada, atingindo, nos genótipos mais suscetíveis, os cultivares IPA-5 e AG-45, taxas de infecção de 17,9 e 14,3\% respectivamente (Quadro 1). Os demais, compreendendo as linhagens do grupo IAC S4, apresentaram índices de infecção inferiores a 3\%, diferindo significativamente dos dois cultivares. Como nessa região só tem sido registrada a ocorrência de GRSV em tomateiro (Nagata et al., 1995; Ávila et al., 1996; A.C. de Ávila, informação pessoal, 1998), há indicação de que as quatro linhagens IAC S4 possam ser resistentes a essa espécie de tospovírus.

Quadro 1. Produtividade, teor de sólidos solúveis (brix) e plantas com sintomas de tospovírus em quatro linhagens e dois cultivares de tomateiro, em condições de campo. Petrolina (PE), 1995, e Campinas (SP), 1995/96

\begin{tabular}{|c|c|c|c|c|c|}
\hline \multirow{3}{*}{$\begin{array}{l}\text { Cultivar/ } \\
\text { Linhagem }\end{array}$} & \multicolumn{3}{|c|}{ Petrolina } & \multirow{2}{*}{\multicolumn{2}{|c|}{$\frac{\text { Campinas }}{\text { Plantas infectadas }^{(1)}}$}} \\
\hline & \multirow{2}{*}{$\begin{array}{l}\text { Produti- } \\
\text { vidade }^{(1)}\end{array}$} & \multirow{2}{*}{$\operatorname{Brix}^{(1)}$} & \multirow{2}{*}{$\begin{array}{c}\text { Plantas } \\
\text { infectadas }^{(1)}\end{array}$} & & \\
\hline & & & & $5 / 1 / 96$ & $30 / 1 / 96$ \\
\hline & t.ha- ${ }^{-1}$ & & & & \\
\hline IPA-5 $\ldots \ldots \ldots \ldots \ldots$ & $42,3 c$ & $4,22 \mathrm{bc}$ & $17,9 \mathrm{a}$ & $89,1 \mathrm{a}$ & $100,0 \mathrm{a}$ \\
\hline AG-45 ............... & $71,2 \mathrm{a}$ & $4,82 \mathrm{a}$ & $14,3 \mathrm{a}$ & $83,3 \mathrm{a}$ & $100,0 \mathrm{a}$ \\
\hline IAC S4-13 ...... & $62,9 \mathrm{ab}$ & $4,12 \mathrm{c}$ & $2,9 b$ & $26,9 b$ & $39,0 \mathrm{~b}$ \\
\hline IAC S4-17 ...... & $70,9 a$ & $4,46 b c$ & $0,7 \mathrm{~b}$ & $2,8 \mathrm{~b}$ & $34,5 b$ \\
\hline IAC S4-3 ........ & $56,4 \mathrm{~b}$ & $4,48 b$ & $0,0 \mathrm{~b}$ & $6,7 b$ & $33,8 b$ \\
\hline IAC S4-4 ......... & $58,4 \mathrm{ab}$ & $4,42 b c$ & $0,0 \mathrm{~b}$ & $2,6 b$ & $29,1 b$ \\
\hline Média ............... & 60,3 & 4,42 & 6,0 & 35,2 & 56,1 \\
\hline $\mathrm{CV}(\%) \ldots \ldots \ldots . .$. & 11,6 & 3,84 & 42,91 & 47,8 & 15,2 \\
\hline
\end{tabular}

(1) Médias seguidas de mesma letra na coluna não diferem significativamente entre si pelo teste de Tukey a $5 \%$. 
Com relação à produtividade (Quadro 1), os genótipos mais produtivos foram 'AG-45', com 71,2 t.ha' ${ }^{-1}$, e IAC S4-17, com 70,9 t.ha ${ }^{-1}$, diferindo significativamente de IAC S4-3 e 'IPA-5', este o menos produtivo e diferindo de todos os demais.

Os valores de Brix variaram de $4,82 \%$, o mais elevado e presente em 'AG-45', a 4,12\%, na IAC S4-13 (Quadro 1). As demais linhagens IAC apresentaram valores sem diferença significativa entre si, em um intervalo de 4,42 a $4,48 \%$.

Considerando-se a produtividade e a porcentagem de plantas com sintomas de infecção por tospovírus, verifica-se o bom comportamento de IAC S4-17, com produção próxima à do melhor tratamento, 'AG-45', além de nível de infecção próximo a zero, bem inferior ao desse cultivar.

\subsection{Avaliação de infecção por tospovírus em linhagens e cultivares, em Campinas (SP), em 1995/96}

Nesse experimento, que envolveu os mesmos tratamentos estudados em Petrolina, a incidência de tospovírus foi mais intensa que naquela localidade, atingindo $100 \%$ de infecção em 'IPA-5' e em 'AG-45', na avaliação final, realizada dois meses após o transplante (Quadro 1). Mesmo na primeira avaliação, ocorrida um mês e pouco do transplante, ambos os cultivares já apresentavam mais de $80 \%$ de plantas com sintomas de infecção, enquanto nas linhagens resistentes IAC S4-4 e IAC S4-17, os valores não atingiam $3 \%$. Na avaliação final, as quatro linhagens resistentes situaram-se em níveis próximos, ao redor de $30-40 \%$, não diferindo significativamente entre si. Níveis dessa grandeza, ou mesmo maiores, já haviam sido observados para tais linhagens em ensaio nessa mesma área em Campinas, em 1994/95, em comparação com material suscetível, que atingiu $100 \%$ de infecção (Lourenção et al., 1997). Observações semelhantes, ou seja, taxas de infecção acima de $30 \%$ devidas a tospovírus em germoplasma considerado resistente, também portador do gene $\mathrm{Sw}-5$, têm sido verificadas em área experimental da SVS, em Paulínia
(SP), onde normalmente ocorrem altas infecções de tospovírus (P.C.T. de Melo, dados não publicados). Esses fatos sugerem a possibilidade de quebra da resistência do gene $\mathrm{Sw}-5$, conforme ocorrido na África do Sul e no Havaí (Thompson \& Zijl, 1996; Stevens et al., 1998) ou a presença de isolados mais agressivos, ou mesmo de novas espécies, de tospovírus na região de Campinas e de Paulínia.

De qualquer forma, tanto em Campinas como em Petrolina, o comportamento dos tratamentos ante a doença foi semelhante. As médias de infecção dos dois cultivares foram significativamente superiores às das quatro linhagens, a despeito da provável diferença de espécies dos tospovírus das duas localidades. A resistência contra espécies distintas de tospovírus, controlada pelo gene $\mathrm{Sw}-5$, foi comprovada no Brasil por Boiteux \& Giordano (1993).

\subsection{Avaliação de infecção por tospovírus em linhagens e cultivares em Campinas (SP), em 1996/97}

Na primeira avaliação do experimento de campo (17/1/97), realizada vinte dias após o transplante, os sintomas de "vira-cabeça" nas parcelas de 'IPA-5' não indicavam suscetibilidade desse cultivar comparativamente aos demais genótipos (Quadro 2). Todavia, na segunda avaliação (6/2/97), as nove seleções feitas nas linhagens do grupo IACS4 apresentaram comportamento diferenciado em relação à testemunha suscetível 'IPA-5', diferindo significativamente desse controle nessa e na avaliação seguinte. Na gleba experimental, as infecções devidas a tospovírus têm, historicamente, sido severas e precoces, levando à morte ou debilitando extremamente, em final de ciclo, as plantas de cultivares ou linhagens suscetíveis, cujas parcelas contrastam fortemente com as de genótipos resistentes. Isso tem reflexo nas avaliações finais, cujos coeficientes de variação, decorrentes de análise estatística, tendem a baixar quando comparados com aqueles de avaliação mais precoces. 
Quadro 2. Plantas com sintomas de tospovírus em dez linhagens e dois cultivares de tomateiro, em condições de campo. Campinas (SP), 1996/97

\begin{tabular}{|c|c|c|c|}
\hline \multirow{2}{*}{$\begin{array}{l}\text { Cultivar/ } \\
\text { Linhagem }\end{array}$} & \multicolumn{3}{|c|}{ Plantas infectadas $^{(1)}$} \\
\hline & $17 / 1 / 97$ & $6 / 2 / 97$ & $12 / 3 / 97$ \\
\hline & & $\%$ & \\
\hline IPA-5 ....................... & $14,4 \mathrm{a}$ & $52,0 \mathrm{a}$ & $90,3 \mathrm{a}$ \\
\hline IAC S4-Bk 96-4 ..... & $8,0 \mathrm{a}$ & $14,7 \mathrm{bc}$ & $29,4 b$ \\
\hline IAC S4-4-17 .............. & $2,6 \mathrm{a}$ & $17,0 \mathrm{~b}$ & $28,9 b$ \\
\hline IAC S4-Bk 96-1 ..... & $9,5 \mathrm{a}$ & $12,3 \mathrm{bc}$ & $27,8 b$ \\
\hline IAC S4-Bk 96-10 ... & $9,5 \mathrm{a}$ & $16,3 b$ & $24,7 b$ \\
\hline IAC S4-17-10 ........... & $0,0 \mathrm{a}$ & $13,8 \mathrm{bc}$ & $24,1 b$ \\
\hline IAC S4 -3-3 .............. & $2,6 a$ & $10,2 b c$ & $20,4 b$ \\
\hline IAC S4-Bk 96-5 ..... & $0,0 \mathrm{a}$ & $1,3 \mathrm{bc}$ & $19,6 b$ \\
\hline IAC S4-3-18 .............. & $0,0 \mathrm{a}$ & $1,3 \mathrm{bc}$ & $15,3 b$ \\
\hline IAC S4-3-10 ............... & $0,0 \mathrm{a}$ & $1,3 \mathrm{bc}$ & $10,4 b$ \\
\hline 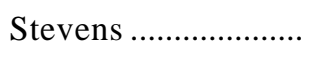 & $0,0 \mathrm{a}$ & $2,8 \mathrm{bc}$ & $9,7 b$ \\
\hline IAC S4-4-16G ......... & $0,0 \mathrm{a}$ & $0,0 \mathrm{c}$ & $9,0 \mathrm{~b}$ \\
\hline Média ............................ & 3,9 & 11,9 & 25,8 \\
\hline $\mathrm{CV}(\%)$ & 41,7 & 25,8 & 11,9 \\
\hline
\end{tabular}

(1) Médias seguidas de mesma letra na coluna não diferem significativamente entre si pelo teste de Tukey a $5 \%$.

No experimento em telado, procurou-se avaliar, quanto à infecção por tospovírus, algumas linhagens derivadas de outras fontes de resistência que não 'Stevens' e que haviam sofrido baixa infecção desse agente em outras áreas do CEC. Na primeira avaliação (6/2/97), quarenta dias após o transplante, já houve discriminação do material estudado, tendo, à exceção de IAC S4-13, todos os genótipos originados de cruzamentos com L. peruvianum diferido significativamente de 'IPA-5' (Quadro 3). Na última avaliação (12/3/97), essa tendência ficou mais marcante, confirmando dados de Lourenção et al. (1997), demonstrando que tanto 'Stevens' como LA 444-1, parental de IAC CNRT-4, IAC CNRT-5, IAC 14-2-49 e IAC 14-2-85, são fontes de resistência que permitem a obtenção de progênies com resistência a tospovírus comparável a elas. Já o desempenho das linhagens derivadas de L. hirsutum, cujo parental é PI 134417, também ratificam observações anteriores de Lourenção et al. (1997), verificando suscetibilidade próxima à dos controles suscetíveis. A linhagem IAC 14-2-49 teve média muito baixa de infecção e pode ser uma opção como fonte de resistência para programas de melhoramento, considerando-se que, atualmente, a maioria dos programas tem utilizado quase que exclusivamente 'Stevens' como parental resistente a tospovírus. Há necessidade de detectar novas fontes de resistência, conforme assinalado por Stevens et al. (1998), os quais discutem também a resistência presente em $L$. chilense a tospovírus.

\subsection{Avaliação de infecção por tospovírus em linhagens e cultivares em Campinas (SP), em 1997/98}

Na primeira avaliação (4/2/98), aos 45 dias do transplante, 'IPA-6' tinha 57,2\% de infecção e diferia, com exceção de 'Colosso', de todos os outros genótipos, cuja maioria não atingia 10\% (Quadro 4). Passados 35 dias, na avaliação final, quando 'IPA-6' atingia $100 \%$ de infecção e tinha a maioria das plantas mortas, os demais tratamentos situavam-se em gradiente que variava de 70,3 ('Colosso') até 8,6\% (IAC S4-4-16G). As nove seleções IAC S4, feitas dentro das melhores plantas do experimento do ano anterior visando a tamanho e dureza dos frutos, apresentaram índices de infecção variando desde 52,7 (IAC S4-3-3-5) até 8,6\% (IAC S4-4-16G), o menor do campo experimental. Entre os germoplasmas desenvolvidos pela SVS para resistência a tospovírus, o cultivar Colosso apresentou o pior desempenho, com 70,3\% de infecção; as linhagens L247-97 (34\%), L248-97 (32,8\%) e L250-97 (28,9\%), embora com infecções médias superiores a IAC S4-4-16G (8,6\%), não diferiram significativamente dessa linhagem.

Especula-se que híbridos heterozigotos ( $\mathrm{Sw}-5$ sw-5) mostram resistência tipicamente intermediária, enquanto os homozigotos ( $\mathrm{Sw}-5 \mathrm{Sw}-5$ ) tendem a exibir níveis significativamente maiores de resistência. Essa diferença pode ser confirmada no presente tra- 
Quadro 3. Plantas com sintomas de tospovírus em treze linhagens e um cultivar de tomateiro, em condições de telado. Campinas (SP), 1996/97

Cultivar/
Linhagem

Plantas infectadas ${ }^{(1)}$

Lycopersicon esculentum

L. esculentum $x$ L. hirsutum

IAC F2-1

IAC F3-1-2 X F3-1-5

IAC F3-1-5

Rey Tempranos x IAC F3-1-5 ...

IAC S4-13 .

IAC CNRT-5

IAC $14-2-85$

IAC CNRT-4

IAC S4-4

IAC S4-3

PI 134417

IAC 14-2-49

IAC S4-17
L. esculentum $x$ L. peruvianum

$"$
$"$
$"$

L. hirsutum

L. esculentum $x$ L. peruvianum

$6 / 2 / 97$
$12 / 3 / 97$

$\%$

(2)

\begin{tabular}{|c|c|c|}
\hline 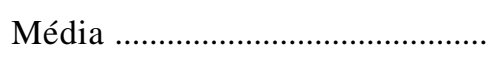 & 11,9 & 33,3 \\
\hline $\mathrm{CV}(\%)$ & 42,4 & 11,8 \\
\hline
\end{tabular}

${ }^{(1)}$ Médias seguidas de mesma letra na coluna não diferem significativamente entre si pelo teste de Tukey a $5 \%$.

balho, já que 'Colosso' é um híbrido heterozigoto e as linhagens L247-97, L248-97 e L250-97 são consideradas como homozigotas para esse gene. A linhagem L355-E, uma seleção de TSW-10, alcançou infecção acima de 50\%, nível nunca verificado para esse material nas condições onde foi desenvolvido (Brasília) e mesmo em Paulínia até o verão de 1997/ 98. Todavia, no verão de 1993/94, TSW-10 sofreu infecção ao redor de $40 \%$ quando avaliada em condições de campo em Campinas (Lourenção et al., 1997), embora tenha sido selecionada para resistência a três espécies de tospovírus, TSWV, TCSV e GRSV (Boiteux et al., 1993), o que reforça as hipóteses de quebra de resistência do gene $\mathrm{Sw}-5$ ou de ocorrência de isolados mais agressivos ou espécies novas na região.

\subsection{Avaliação de produtividade e de teor de sólidos solúveis em linhagens em Patos de Minas (MG), em 1997}

Nessa localidade, não se constatou a incidência de tospovírus na gleba experimental. As duas linhagens apresentaram, em ambas as épocas de plantio, crescimento vegetativo vigoroso, com ciclo longo, embora tenham sido produtivas e com frutos de boa qualidade (Quadro 5). Essas características de ciclo e de crescimento desfavoráveis não foram observadas na linhagem IAC S4-3, da qual se selecionaram IAC S4-3-10 e IAC S4-3-18H, no experimento em Petrolina em 1995. Possivelmente se trate de problema de adaptação ao cerrado, em vista das baixas temperaturas e luminosidade que ocorrem no inverno nesse agroecossistema. 
Quadro 4. Plantas com sintomas de tospovírus em treze linhagens e três cultivares de tomateiro, em condições de campo. Campinas (SP), 1997/98

\begin{tabular}{lcc}
\hline Cultivar/ & \multicolumn{2}{c}{ Plantas infectadas } \\
\cline { 2 - 3 } Linhagem & $4 / 2 / 98$ & $11 / 3 / 98$ \\
\hline & & \multicolumn{2}{c}{$\%$} & \\
\cline { 2 - 3 } IPA-6 .............. & $57,2 \mathrm{a}$ & $100,0 \mathrm{a}$ \\
Colosso ............ & $15,8 \mathrm{ab}$ & $70,3 \mathrm{~b}$ \\
L355-E ............ & $7,8 \mathrm{~b}$ & $55,1 \mathrm{bc}$ \\
IAC S4-3-3-5 .... & $5,0 \mathrm{~b}$ & $52,7 \mathrm{bcd}$ \\
IAC S4-3-10 ..... & $14,6 \mathrm{~b}$ & $39,0 \mathrm{~b}-\mathrm{e}$ \\
L247-97 ........... & $14,4 \mathrm{~b}$ & $34,0 \mathrm{~b}-\mathrm{e}$ \\
L248-97 .......... & $11,1 \mathrm{~b}$ & $32,8 \mathrm{~b}-\mathrm{e}$ \\
IAC S4-3-18E... & $7,7 \mathrm{~b}$ & $32,2 \mathrm{~b}-\mathrm{e}$ \\
Stevens ............. & $3,7 \mathrm{~b}$ & $31,7 \mathrm{~b}-\mathrm{e}$ \\
IAC S4-3-18B ... & $7,6 \mathrm{~b}$ & $30,7 \mathrm{~b}-\mathrm{e}$ \\
L250-97 ........... & $6,7 \mathrm{~b}$ & $28,9 \mathrm{~b}-\mathrm{e}$ \\
IAC S4-3-18H ... & $1,8 \mathrm{~b}$ & $27,9 \mathrm{cde}$ \\
IAC S4-4-4 ....... & $7,7 \mathrm{~b}$ & $26,7 \mathrm{cde}$ \\
IAC S4-4-18C ... & $2,1 \mathrm{~b}$ & $20,7 \mathrm{cde}$ \\
IAC S4-4-16A ... & $9,3 \mathrm{~b}$ & $19,2 \mathrm{de}$ \\
IAC S4-4-16G ... & $1,9 \mathrm{~b}$ & $8,6 \mathrm{e}$ \\
\hline Média .............. & 10,9 & 38,2 \\
CV $\%$............. & 40,26 & 33,2 \\
\hline
\end{tabular}

(1) Médias seguidas de mesma letra na coluna não diferem significativamente entre si pelo teste de Tukey a $5 \%$.
Com relação ao brix, o cultivar AG-45 teve a maior média $(4,60 \%)$, o que já havia sido constatado no experimento de Petrolina, em 1995 (Quadro 1), embora sem diferir das duas linhagens IAC. As médias de produtividade, também para as duas épocas de semeadura, indicaram comportamento superior para as linhagens IAC, cujos valores foram maiores que os dos dois cultivares, apesar de apresentarem elevado número de frutos verdes e podres.

Com base nos resultados das três localidades, sugere-se que as linhagens do grupo IAC S4, derivadas de 'Stevens', possam ter resistência a mais de uma espécie de tospovírus, embora não tenham sido feitas identificações dos isolados. Essa resistência a diferentes isolados de tospovírus, controlada pelo gene Sw-5, foi discutida por Zijl et al. (1986), Stevens et al. (1992), Boiteux \& Giordano (1993), Giordano et al. (1994) e, mais recentemente, por Gebre-Selassie et al. (1998). Esses últimos autores, trabalhando com 58 isolados de TSWV obtidos de diferentes hospedeiros e localidades da França, Bélgica, Itália, Espanha, Portugal e Ilhas Reunião, e um isolado do Brasil (TSWV-BR-01), inoculados mecanicamente nos cultivares Stevens e Momor, não detectaram nenhum isolado entre os testados capaz de quebrar a resistência em 'Stevens', diferentemente do ocorrido na África do Sul e no Havaí (Thompson \& Zijl, 1996; Stevens et al., 1998).

Quadro 5. Teor de sólidos solúveis (brix) e produtividade de duas linhagens e dois cultivares de tomateiro em duas épocas de plantio, em condições de campo. Patos de Minas (MG), 1997

\begin{tabular}{|c|c|c|c|c|c|c|}
\hline \multirow{2}{*}{$\begin{array}{l}\text { Cultivar/ } \\
\text { Linhagem }\end{array}$} & \multicolumn{3}{|c|}{ Brix $^{(1)}$} & \multicolumn{3}{|c|}{ Produtividade ${ }^{(1)}$} \\
\hline & $4 / 97$ & $5 / 97$ & Média & $4 / 97$ & $5 / 97$ & Média \\
\hline & \multicolumn{3}{|c|}{$\longrightarrow \%$} & \multicolumn{3}{|c|}{$-\mathrm{t} \cdot \mathrm{ha}^{-1}$} \\
\hline IAC S4-3-10 ....... & 4,8 & 4,1 & $4,45 \mathrm{ab}$ & 116,1 & 116,0 & $116,0 \mathrm{a}$ \\
\hline IAC S4-3-18H ... & 4,7 & 3,5 & $4,10 \mathrm{ab}$ & 116,3 & 100,2 & $108,2 \mathrm{a}$ \\
\hline IPA-5 ..................... & 3,9 & 3,8 & $3,85 b$ & 97,1 & 87,4 & $92,2 b$ \\
\hline $\mathrm{AG}-45 \ldots \ldots \ldots \ldots \ldots$ & 4,6 & 4,6 & $4,60 \mathrm{a}$ & 82,9 & 76,1 & $79,5 \mathrm{c}$ \\
\hline Média .................... & $4,5 \mathrm{~A}$ & $4,0 \mathrm{~B}$ & - & $103,1 \mathrm{~A}$ & $94,9 \mathrm{~B}$ & - \\
\hline $\mathrm{CV}(\%) \ldots \ldots \ldots \ldots \ldots$ & - & - & 8,79 & - & - & 5,97 \\
\hline
\end{tabular}

${ }^{(1)}$ Médias seguidas de mesma letra, maiúscula na linha e minúscula na coluna, não diferem significativamente entre si pelo teste de Tukey a $5 \%$. 
Há necessidade de testar as linhagens do grupo IAC S4 mediante inoculação contra todas as espécies de tospovírus disponíveis, para conhecer a extensão de sua resistência e, a partir daí, seu uso potencial como cultivares ou como linhagens em programas de melhoramento. Também se infere que, apesar de apresentar resistência a tospovírus e comportamento agronômico favorável em Campinas e em Petrolina, essas linhagens poderão não se adaptar a plantios em diferentes regiões do País, pelas condições edafoclimáticas específicas locais, conforme observações feitas em Patos de Minas em 1997.

\section{REFERÊNCIAS BIBLIOGRÁFICAS}

ÁVILA, A.C. de; LIMA, M.F.; RESENDE, R. de O.; POZZER, L.; FERRAZ, E.; MARANHÃO, E.A.A.; CANDEIA, J.A. \& COSTA, N.D. Identificação de tospovírus em hortaliças no Submédio São Francisco utilizando DASELISA e DOT-ELISA. Fitopatologia Brasileira, Brasília, 21(4):503-508, 1996.

ÁVILA, A.C. de; POZZER, L.; BEZERRA, I.; KORMELINK, R.; PRINS, M.; PETERS, D.; NAGATA, T.; KITAJIMA, E. \& RESENDE, R. Diversity of tospoviruses in Brazil. In: INTERNATIONAL SYMPOSIUM ON TOSPOVIRUSES AND THRIPS IN FLORAL AND VEGETABLECROPS, 4., Wageningen, 1998. Abstracts, Wageningen, 1998. p.32-34.

BOITEUX, L.S. \& GIORDANO, L. de B. Genetic basis of resistance against two Tospovirus species in tomato (Lycopersicon esculentum). Euphytica, Dordrecht, 71:151-154, 1993.

BOITEUX, L.S.; GIORDANO, L. de B.; ÁVILA, A.C. de \& SANTOS, J.R.M. 'TSW-10': linhagem de tomate para mesa resistente a três espécies de tospovírus causadores do "vira-cabeça". Horticultura Brasileira, Brasília, 11(2):163-164, 1993.

COSTA, A.S. \& FORSTER, R. A transmissão mecânica de vira-cabeça por fricção com suco. Revista de Agricultura, Piracicaba, 13:249-262, 1938.
GEBRE-SELASSIE, K.; MOURY, B.; PALLOIX, A. \& MARCHOUX, G. Variability of tomato spotted wilt virus isolates in relation with stability of resistance on pepper and tomato genotypes. In: INTERNATIONAL SYMPOSIUM ON TOSPOVIRUSES AND THRIPS IN FLORAL AND VEGETABLE CROPS, 4., Wageningen, 1998. Abstracts, Wageningen, 1998. p.16-18.

GERMAN, T.L.; ULLMAN, D.E. \& MOYER, J.W. Tospoviruses: diagnosis, molecular biology, phylogeny, and vector relationships. Annual Review of Phytopathology, Palo Alto, 30:315-348, 1992.

GIORDANO, L. de B.; BOITEUX, L.S. \& HORINO, Y. Avaliação em condições de campo de genótipos de tomate para resistência a tospoviroses. Horticultura Brasileira, Brasília, 12(2):176-178, 1994.

GIORDANO, L. de B.; LIMA, M.I.; RESENDE, R. de O.; FERRAZ, E. \& ÁVILA, A.C. de. Developing tomato cultivars with resistance to tospovirus. In: INTERNATIONAL SYMPOSIUM ON TOSPOVIRUSES AND THRIPS IN FLORAL AND VEGETABLE CROPS, 4., Wageningen, 1998. Abstracts, Wageningen, 1998. p.97.

IE, T.S. Tomato spotted wilt virus. Richmond, Commonwealth Mycological Institute/ Association of Applied Biologists (C.M.I./ A.A.B.), 1970. 4p. (Description of Plant Viruses, 39)

JULIATTI, F.C. \& MALUF, W.R. Controle genético da resistência do tomateiro a um isolado de tospovírus (TSWV): análise em plantas individuais. Fitopatologia Brasileira, Brasília, 20(1):39-47, 1995.

JULIATTI, F.C.; MALUF, W.R. \& FIGUEIRA, A. R. Reação de linhagens avançadas de tomateiro a isolados de tospovírus. Fitopatologia Brasileira, Brasília, 19(1):6268, 1994.

JULIATTI, F.C.; MALUF, W.R.; GOULART, L.R. \& RESENDE, R.O. Seleção de progênies resistentes a um isolado de tospovírus em Lycopersicon esculentum. Fitopatologia Brasileira, Brasília, 21(2):167-172, 1996.

LOURENÇÃO, A.L.; NAGAI, H.; SIQUEIRA, W.J.; USBERTI FILHO, J.A. \& MELO, A.M.T. de. Seleção de tomateiros resistentes a tospovírus. Bragantia, Campinas, 56(1):21-31, 1997.

MALUF, W.R.; BRAGHINI, M.T. \& CORTE, R.D. Progress in breeding tomatoes for resistance to tomato spotted wilt. Revista Brasileira de Genética, São Paulo, 14(2):509-525, 1991. 
MELO, P.C.T. de \& CARNEIRO, L. Tomato breeding for tospovirus resistance for Brazilian subtropical and tropical conditions. In: INTERNATIONAL CONFERENCE ON THE PROCESSING TOMATO and INTERNATIONAL SYMPOSIUM ON TROPICAL TOMATO DISEASES, 1., Recife, 1996. Proceedings. Alexandria, ASHS Press, 1997. p.172-173.

NAGAI, H.; LOURENÇÃO, A. L. \& SIQUEIRA, W.J. Tomato breeding for resistance to diseases and pests in Brazil. Acta Horticulturae, Wageningen, 301:91-97, 1992.

NAGATA, T.; ÁVILA, A.C. de; TAVARES, P.C. de M.; BARBOSA, C. de J.; JULIATTI, F.C. \& KITAJIMA, E.W. Occurrence of different tospoviruses in six States of Brazil. Fitopatologia Brasileira, Brasília, 20(1):9095, 1995.

POZZER, L.; RESENDE, R.O.; LIMA, M.I.; KITAJIMA, E.W.; GIORDANO, L.B. \& ÁVILA, A.C. Tospovírus: uma visão atualizada. Revisão Anual de Patologia de Plantas, Passo Fundo, 4:95-148, 1996.

RESENDE, L.V.; FERRAZ, E.; FRANÇA, J.G.E.; QUILOMBO, H.A. \& SILVA, A.A.S. Identification and selection of processing tomato genotypes resistant to tospovirus. In: SCIENTIFIC SIMPOSIUM ON THE PROCESSING TOMATO, 6., Pamplona, 1998. Abstracts, 1998. p.105-106.
RESENDE, L.V.; MALUF, W.R. \& RESENDE, J.T.V. Combining ability and heterosis among tomato plant lines with different levels and genetic control of resistance to tospovirus. In: INTERNATIONAL CONFERENCE ON THE PROCESSING TOMATO and INTERNATIONAL SYMPOSIUM ON TROPICAL TOMATO DISEASES, 1., Recife, 1996. Proceedings. Alexandria, 1997. p.187.

STEVENS, M.R.; CANADY, M. \& BARINEAU, M. What we know about tospovirus resistance in tomato (Lycopersicon esculentum) derived from the wild species L. chilense. In: INTERNATIONAL SYMPOSIUM ON TOSPOVIRUSES AND THRIPS IN FLORAL AND VEGETABLE CROPS, 4., Wageningen, 1998. Abstracts, Wageningen, 1998. p.19-20.

STEVENS, M.R.; SCOTT, S.J. \& GERGERICH, R.C. Inheritance of a gene for resistance to tomato spotted wilt virus (TSWV) from Lycopersicon peruvianum Mill. Euphytica, Dordrecht, 59:9-17, 1992.

THOMPSON, G.J. \& ZIJL, J.J.B. van. Control of tomato spotted wilt virus in tomatoes in South Africa. Acta Horticulturae, Wageningen, 431:379-384, 1996.

WIJKAMP, I.; ALMARZA, N.; GOLDBACH, R. \& PETERS, D. Distinct levels of specificity in thrips transmission of tospoviruses. Phytopathology, St. Paul, 85(10):10691074, 1995.

ZIJL, J.J.B. van; BOSCH, S.E. \& COETZEE, C.P.J. Breeding tomatoes for processing in South Africa. Acta Horticulturae, Wageningen, 194:69-75, 1986. 